\title{
Cation ratio and oxygen defects for engineering the magnetic transition of monodisperse nonstoichiometric zinc ferrite nanoparticles
}

\author{
${\text { Yong } \operatorname{Sun}^{1 \dagger} \text {, Xia Deng }}^{3 \dagger}$, Yan Zong ${ }^{1,2}$, Xinghua $\mathrm{Li}^{1,2^{*}}$, Junwei Zhang ${ }^{4}$, Juan Feng ${ }^{1,2}$, Xiao Chi ${ }^{5^{*}}$, \\ Zhenhua Shi ${ }^{6}$, Xinliang Zheng ${ }^{1,2}$ and Yong Peng ${ }^{4 *}$
}

\begin{abstract}
Monodisperse nonstoichiometric zinc ferrite nanoparticles with a tunable size of 4.1-32.2 $\mathrm{nm}$ are fabricated via thermal decomposition. An extrinsic impurity phase of the $\mathrm{ZnO}$ component is present in the zinc ferrite nanoparticles with a size of $<10 \mathrm{~nm}$, but this phase can be eliminated after the air annealing treatment. The atom ratio of $\mathrm{Zn} / \mathrm{Fe}$ and concentration of oxygen vacancies decrease as the particle size of zinc ferrite increases, causing magnetic transition from superparamagnetism to ferromagnetism. The $\mathrm{X}$-ray magnetic circular dichroism spectra reveal that the spin magnetic moments of $\mathrm{Fe}^{3+}$ are reduced, and the orbital magnetic moments are frozen with the increasing atom ratio of $\mathrm{Zn} / \mathrm{Fe}$. Therefore, saturation magnetization decreases. The saturation magnetizations of all the zinc ferrite nanoparticles decrease after the air annealing treatment, suggesting that oxygen vacancies considerably influence the magnetic properties. The air annealing treatment can minimize the number of oxygen defects, which trigger some of the $\mathrm{Fe}^{3+}-\mathrm{O}_{\mathrm{V}}-\mathrm{Fe}^{3+}$ ferrimagnetic couplings to transfer into the $\mathrm{Fe}^{3+}-\mathrm{O}^{2-}-\mathrm{Fe}^{3+}$ antiferromagnetic couplings. This work provides new insights regarding the magnetic performance of spinel ferrites by tuning the stoichiometric ratio and oxygen defects.
\end{abstract}

Keywords: zinc ferrite, nonstoichiometric, magnetic transition, oxygen defects

\section{INTRODUCTION}

As important magnetic materials, spinel ferrites $\left(\mathrm{MFe}_{2} \mathrm{O}_{4}\right.$,
$\mathrm{M}=\mathrm{Co}, \mathrm{Ni}, \mathrm{Mn}, \mathrm{Cu}, \mathrm{Zn}$, etc.) have been widely used in fundamental magnetic investigations and technical applications in high-density magnetic storage [1], environmental remediation [2], catalysis [3], ferrofluids [4], and microwave absorption $[5,6]$ because of their special magnetic properties, inoxidizability, chemical/physical stability, nontoxicity, and biocompatibility. For instance, Hou et al. [7-9] reported that spinel ferrite nanostructures can be applied in biomedical applications requiring high magnetization. Spinel ferrites have a chemical formula of $\left(\mathrm{M}_{1-\delta} \mathrm{Fe}_{\delta}\right)\left[\mathrm{M}_{\delta} \mathrm{Fe}_{2-\delta}\right] \mathrm{O}_{4}$, where $\mathrm{O}^{2-}$ constitutes a close-packed cubic lattice with two sublattices of tetrahedron and octahedron. The round and square brackets represent the metal ions located at tetrahedral sites (A sites) and octahedral sites (B sites), respectively. $\delta$ is the inverse degree, which is generally determined based on the fraction of $\mathrm{Fe}^{3+}$ at the A site. According to the sublattice theory [10], the magnetic moments at the A sites are antiparallel with those at the B sites and net magnetic moments are the difference between the magnetic moments at the A and $\mathrm{B}$ sites [1113]. Therefore, the cation distributions at the $\mathrm{A}$ and $\mathrm{B}$ sites influence the magnetic properties of ferrites, including magnetization, blocking temperature, and effective $\mathrm{g}$ factors $[14,15]$.

Bulk stoichiometric zinc ferrite $\left(\mathrm{ZnFe}_{2} \mathrm{O}_{4}\right)$ is a representative normal spinel ferrite $(\delta=0)$, where all the $\mathrm{Fe}^{3+}$ ions at the $\mathrm{B}$ sites and all the $\mathrm{Zn}^{2+}$ ions are found at

\footnotetext{
${ }^{1}$ School of Physics, Northwest University, Xi'an 710069, China

${ }^{2}$ State Key Laboratory of Photon Technology in Western China Energy, Northwest University, Xi'an 710069, China

${ }^{3}$ School of Life Science and Electron Microscopy Center of Lanzhou University, Lanzhou University, Lanzhou 730000, China

${ }^{4}$ Key Laboratory of Magnetism and Magnetic Materials of the Ministry of Education, Lanzhou University, Lanzhou 730000, China

${ }^{5}$ National University of Singapore, Singapore Synchrotron Light Source, 5 Res Link, Singapore 117603, Singapore

${ }^{6}$ School of Science, Xi'an Technological University, Xi'an 710021, China

$\dagger$ These authors contributed equally to this work.

* Corresponding authors (emails: xinghua.li@nwu.edu.cn (Li X); chixiao1016@gmail.com (Chi X); pengy@lzu.edu.cn (Peng Y))
} 
the A sites [10]. The $d$ shells of $\mathrm{Zn}^{2+}$ at the $\mathrm{A}$ sites are fulfilled without unpaired electrons, which exhibit no magnetic moment. The magnetic moments of $\mathrm{Fe}^{3+}$ at the $B$ sites tend to be antiparallel, resulting in zero net magnetic moment. The total magnetic moments of $\mathrm{ZnFe}_{2} \mathrm{O}_{4}$ become zero with this specific lattice structure. Bulk $\mathrm{ZnFe}_{2} \mathrm{O}_{4}$ shows an antiferromagnetic feature and a paramagnetic characteristic below and above Néel temperature $(10.5 \mathrm{~K})$, respectively [16-18]. Néel [19] predicted that the reducing particle size of the antiferromagnetic materials may induce ferromagnetism because of the uncompensated magnetic spins on the surface. Further, $\mathrm{ZnFe}_{2} \mathrm{O}_{4}$ nanostructures with various morphological characteristics have been fabricated through different mechanisms, including coprecipitation [20], hydrothermal route [21], ball milling [22], sol-gel method [23], and thermal decomposition [14,18,24]. Anomalous superparamagnetism or ferromagnetism can be observed when the particle size is in the nanometer range [25]. Particle size reduction can induce $\mathrm{Zn}^{2+}$ redistribution at the $\mathrm{A}$ or $\mathrm{B}$ sites; therefore, some $\mathrm{Fe}^{3+}$ ions transfer from the B sites to A sites, resulting in uncancelled magnetic moments [26-33]. However, the magnetic properties of stoichiometric zinc ferrite nanoparticles are poor; for example, saturation magnetization is usually less than $5 \mathrm{emu} \mathrm{g}^{-1}$ [34]. Zinc is beneficial for human physiology; as such, zinc ferrite shows potential for application in the field of biomedicine. However, the poor magnetization of the stoichiometric zinc ferrite nanoparticles limits their applications $[8,9]$. On the contrary, the magnetic properties of nonstoichiometric zinc ferrite are observed to improve. For example, Han et al. [35] fabricated $\mathrm{Zn}_{0.417} \mathrm{Fe}_{2.583} \mathrm{O}_{4}$ nanoparticles with a high saturation magnetization of $106 \mathrm{emu} \mathrm{g}^{-1}$. Yang et al. [14] synthesized $\mathrm{Zn}_{0.468} \mathrm{Fe}_{2.532} \mathrm{O}_{4}$ nanoparticles with an extraordinary saturation magnetization of $110 \mathrm{emu} \mathrm{g}{ }^{-1}$. Majority of the previously conducted studies have focused on the fabrication of Fe-rich nonstoichiometric zinc ferrite $\left(\mathrm{Zn}_{x} \mathrm{Fe}_{3-x} \mathrm{O}_{4}, x<1.0\right)$ [14,35-37]. The obtained results suggest that $\mathrm{Zn}$ substitution can induce the redistribution of Fe ions at the tetrahedral and octahedral sites, resulting in the tunable magnetic properties. Makovec et al. [38] prepared nonstoichiometric zinc ferrite with a $\mathrm{Zn} / \mathrm{Fe}$ ratio of 0-1.6. Oxygen defects can be observed when $\mathrm{Zn} / \mathrm{Fe}$ is greater than 0.5 , which may destroy the super-exchange interactions and decrease magnetization. However, the intrinsic nature of ferromagnetism in nonstoichiometric zinc ferrite remains unclear. It is still difficult to understand the origin of magnetic properties in nonstoichiometric zinc ferrite. This may provide the basis for designing spinel ferrites with desired magnetic properties. In this work, monodisperse nonstoichiometric zinc ferrite nanoparticles with different cation contents are fabricated through thermal decomposition. The nanostructures and magnetic properties are characterized in detail, and the related magnetic origin is calculated using the density functional theory (DFT). Results indicate that the $\mathrm{Zn} / \mathrm{Fe}$ ratio and oxygen defects considerably influence the magnetic properties of zinc ferrites. This work provides novel insights regarding the preparation of nonstoichiometric zinc ferrite nanoparticles with high magnetization, thereby contributing to the expansion of their applications.

\section{EXPERIMENTAL SECTION}

\section{Chemicals}

The following chemicals were used in this study: zinc acetylacetonate $\left(\mathrm{Zn}(\mathrm{acac})_{2}, 99 \%\right.$; Acros Organics); iron acetylacetonate $\left(\mathrm{Fe}(\mathrm{acac})_{3}, 99 \%\right.$; Alfa Aesar), oleic acid $\left(\mathrm{C}_{18} \mathrm{H}_{34} \mathrm{O}_{2}, 90 \%\right.$; Alfa Aesar), benzyl ether $\left(\mathrm{C}_{12} \mathrm{H}_{10} \mathrm{O}, 98 \%\right.$; Alfa Aesar) and oleylamine $\left(\mathrm{C}_{18} \mathrm{H}_{37} \mathrm{~N}, 50 \%\right.$; TCI). All the chemicals were utilized as received without any further purification.

\section{Synthesis of zinc ferrite nanoparticles}

Zinc ferrite nanoparticles were fabricated via thermal decomposition. In a typical process, $\mathrm{Fe}(\mathrm{acac})_{3}(2 \mathrm{mmol})$, $\mathrm{Zn}(\mathrm{acac})_{2}(1 \mathrm{mmol})$, oleic acid $(x \mathrm{mmol}, x=1,5,6,9)$, and oleylamine $(12-x \mathrm{mmol})$ were gradually added and dissolved in benzyl ether $(20 \mathrm{~mL})$ under magnetic stirring to obtain a brown solution. Under argon flow, the solution was heated to $393 \mathrm{~K}$ within $15 \mathrm{~min}$ and maintained at this temperature for $60 \mathrm{~min}$. At $393 \mathrm{~K}$, the solution was completely deoxidized and dehydrated. The solution was subsequently heated to $473 \mathrm{~K}$ within $10 \mathrm{~min}$ and maintained at this temperature for another $60 \mathrm{~min}$. During this process, the color of the solution gradually changed from brown to black. Subsequently, the solution was heated from 473 to $573 \mathrm{~K}$ at a heating rate of $8 \mathrm{~K} \mathrm{~min}^{-1}$ and refluxed for $60 \mathrm{~min}$. Finally, the solution was cooled to room temperature by switching off the heat source. The products were deposited by adding $20 \mathrm{~mL}$ of isopropanol to the solution and precipitated through high-speed centrifugation $(10,000 \mathrm{rpm}$ for $3 \mathrm{~min})$. The samples were purified and washed using hexane/isopropanol (1:1 vol) three times. Under the same condition, four samples were prepared by changing the ratios of oleic acid and oleylamine to $1: 11,5: 7,9: 3$, and 6:6, which were marked as $S 1$, S2, S3, and S4, respectively. 


\section{Chracterizations}

The samples were characterized using an X-ray diffraction (XRD) instrument with $\mathrm{Cu} \mathrm{Ka}$ radiation $(\lambda=1.5418 \AA$; DX-2700, Hao Yuan, China), a transmission electron microscope (TEM, FEI Tecnai G2 F20), a spherical aberration-corrected electron microscope (FEI Titan Themes Cubed G2 300), an inductively coupled plasma emission spectrometer (ICP, THEM), and an X-ray photoelectron spectrometer (XPS, ESCALAB210). Further, the magnetic properties were characterized using a superconducting quantum interference device (SQUID, MPMS-XL, Quantum Design) and X-ray magnetic circular dichroism (XMCD).

\section{RESULTS AND DISCUSSION}

The XRD patterns of all the four samples are presented in Fig. S1. The diffraction peaks at $29.9^{\circ}, 35.2^{\circ}, 42.8^{\circ}, 53.1^{\circ}$, $56.6^{\circ}$, and $62.1^{\circ}$ correspond to the (220), (311), (400), (422), (511), and (440) crystalline planes, respectively, of zinc ferrite with a cubic spinel structure, which has an $F d 3 m$ space group (JCPDS card No. 74-2397). The dif- fraction peaks strengthen and sharpen from S1 to S4, indicating an enlargement in grain size. The grain sizes of S1, S2, S3, and S4 obtained using Scherrer's equation are 5.0, 7.1, 18.3, and $23.8 \mathrm{~nm}$, respectively. The redundant inconspicuous diffraction peaks at $31.7^{\circ}, 34.4^{\circ}$, and $36.2^{\circ}$ in $\mathrm{S} 1$ and $\mathrm{S} 2$ can be indexed to $\mathrm{ZnO}$ with a wurtzite structure (JCPDS card No. 36-1451), indicating that both these samples contain some $\mathrm{ZnO}$ impurities. Table S1 summarizes the lattice parameters and crystalline sizes of the zinc ferrite nanoparticles. In addition, the $\mathrm{Zn} / \mathrm{Fe}$ ratios of the four samples were quantitatively analyzed through ICP spectroscopy (Table S1). The zinc ferrites are nonstoichiometric, and the atomic ratio of $\mathrm{Zn} / \mathrm{Fe}$ decreases from S1 to S4.

Fig. 1a-d present the representative TEM images of zinc ferrite nanoparticles. All the zinc ferrite nanoparticles are almost monodispersed with good dispersibility. This characteristic is mainly attributed to electrostatic and steric repulsions, which are provided by the long-chain alkyl surfactants on the particle surfaces. The corresponding histograms of particle size (inset of
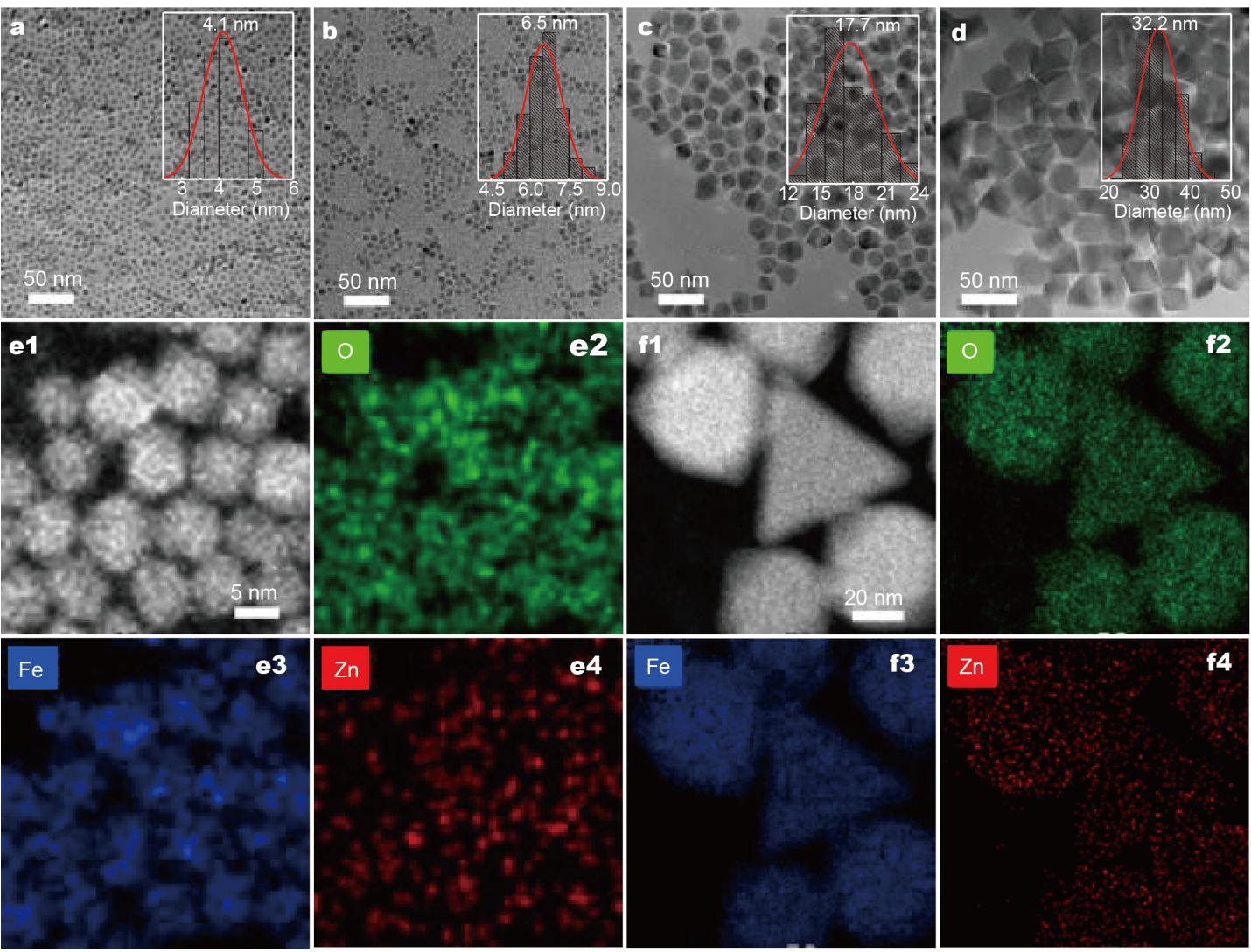

Figure 1 TEM images of (a) S1, (b) S2, (c) S3, and (d) S4. Insets show the corresponding histograms of particle size. HAADF-STEM images and corresponding EDX element mappings of (e) S1 and (f) S4. 
Fig. 1a-d) indicate uniform particles with a narrow size distribution. The average particle sizes of S1, S2, S3, and $\mathrm{S} 4$ are $4.1,6.5,17.7$, and $32.2 \mathrm{~nm}$, respectively (Table $\mathrm{S} 1$ ). Fig. 1e shows the high-angle annular dark field-scanning transmission electron microscopy (HAADF-STEM) image and the corresponding energy disperse spectroscopy (EDS) element mappings of approximately 20 nanoparticles in S1. No single $\mathrm{ZnO}$ nanoparticle can be observed in $\mathrm{S} 1$. However, the $\mathrm{O}$ and $\mathrm{Zn}$ regions are slightly larger than the Fe region. The HAADF-STEM images and EDS element mappings of two other smaller areas of S1 (Figs S2 and S3) containing five and three nanoparticles of S1 were examined to verify this result. The obtained results reveal that the $\mathrm{O}$ and $\mathrm{Zn}$ regions are larger than the Fe region; further, the area of the Fe region is less than the corresponding area in the HAADFSTEM image. In S1, the zinc ferrite nanoparticles may be coated with a layer of $\mathrm{ZnO}$ impurities. Fig. If presents the HAADF-STEM image and the corresponding EDS element mappings of $\mathrm{S} 4$. Fe, $\mathrm{Zn}$, and $\mathrm{O}$ are uniformly distributed in the whole region of nanoparticles.

The atomic resolution images of the individual nanoparticles are characterized through the aberration-corrected STEM technology to identify the cation occupation and structure of S1 with a nonstoichiometric ratio of $\mathrm{Zn}_{1.186} \mathrm{Fe}_{1.814} \mathrm{O}_{4}$. Fig. 2a-c show the atomic HAADFSTEM images of three typical particles for S1. The crystallographic orientations of the three particles are [011], [111], and [112] in the spinel zinc ferrite. Fig. $2 \mathrm{~d}-\mathrm{f}$ display the corresponding line intensity profiles of the atomic columns in Fig. 2 a-c. A $4 \times 4 \times 8$ supercell with $38 \mathrm{Zn}^{2+}$ ions and $58 \mathrm{Fe}^{3+}$ ions was developed to satisfy the $\mathrm{Zn} / \mathrm{Fe}$ ratio of $S 1$ and identify the cation distributions in nonstoichiometric zinc ferrites. Among the transition metal ions, $\mathrm{Zn}^{2+}$ exhibits the strongest preference to occupy the A sites. We assume that $32 \mathrm{Zn}^{2+}$ ions primarily occupy the A sites, whereas the six residual $\mathrm{Zn}^{2+}$ ions and all the 58 $\mathrm{Fe}^{3+}$ ions occupy the $\mathrm{B}$ sites. Fig. $2 \mathrm{~g}-\mathrm{i}$ present the perspective view of the $\mathrm{Zn}_{38} \mathrm{Fe}_{58} \mathrm{O}_{128}$ supercell along the [011], [111], and [112] orientations. The corresponding theoretical STEM images projected along the [011], [111], and [112] zone axes were simulated through quantitative TEM/STEM simulation (QSTEM) (Fig. 2j-l). The relative intensity variations of the simulated HAADF-STEM images (Fig. $2 \mathrm{~m}-\mathrm{O}$ ) are almost similar to those of the experimental HAADF-STEM images (Fig. 2d-f) under identical orientations. These observations indicate that the simulated results agree with the experimental results. Therefore, $\mathrm{Zn}^{2+}$ prioritizes occupying the $\mathrm{A}$ sites in nonstoichiometric zinc ferrites. Fig. S4 shows the atomic HAADF-STEM image of S4 in the perspective view along the [111] orientation.

Fig. 3 showsthe XPS spectra of S1 and S4. The survey scans (Fig. 3a) reveal that both the samples include $\mathrm{O}, \mathrm{Fe}$, and $\mathrm{Zn}$. The $\mathrm{C}$ signal can be attributed to the conductive adhesive substrate. The intensity ratio of the $\mathrm{Zn}$ and $\mathrm{Fe}$ signals for $\mathrm{S} 1$ is stronger than that associated with $\mathrm{S} 4$, and this observation is consistent with the ICP results (Table S1). Fig. 3b presents the representative highresolution Fe 2p spectra of S1 and S4, which can be fitted with six peaks. The main peaks located at approximately 711.8 and $725.4 \mathrm{eV}$ can be attributed to the $\mathrm{Fe} 2 \mathrm{p}_{3 / 2}$ and $\mathrm{Fe} 2 \mathrm{p}_{1 / 2}$ of $\mathrm{Fe}^{3+}$, respectively, whereas the peaks at 709.9 and $723.7 \mathrm{eV}$ can be attributed to the $\mathrm{Fe} 2 \mathrm{p}_{3 / 2}$ and $\mathrm{Fe} 2 \mathrm{p}_{1 / 2}$ of $\mathrm{Fe}^{2+}$, respectively. The two residual peaks at 732.8 and $718.0 \mathrm{eV}$ are satellite peaks [39]. Similarly, the highresolution Fe $2 p$ spectra of all the samples can be fitted with six peaks (Fig. S5). Table S2 presents the corresponding fitting parameters of the Fe 2p XPS spectra. Results indicate the coexistence of $\mathrm{Fe}^{2+}$ and $\mathrm{Fe}^{3+}$ in all the four samples, and $\mathrm{Fe}^{3+}$ is the main component. The $\mathrm{Fe}^{2+} / \mathrm{Fe}^{3+}$ ratios decrease from $\mathrm{S} 1$ to $\mathrm{S} 4$ with the decreasing $\mathrm{Zn} / \mathrm{Fe}$ ratio in nonstoichiometric zinc ferrites. Fig. S6 shows the electron energy loss spectroscopy (EELS) spectra of $\mathrm{O}$ and $\mathrm{Fe}$, indicating the coexistence of $\mathrm{Fe}^{2+}$ and $\mathrm{Fe}^{3+}$ in the samples. Fig. $3 \mathrm{c}$ presents the typical high-resolution $\mathrm{Zn} 2 \mathrm{p}$ spectra of S1 and S4. The two peaks at 1022.4 and $1045.5 \mathrm{eV}$ correspond to the $\mathrm{Zn} 2 \mathrm{p}_{3 / 2}$ and $\mathrm{Zn} 2 \mathrm{p}_{1 / 2}$ of $\mathrm{Zn}^{2+}$, respectively. Fig. $2 \mathrm{~d}$ presents the high-resolution $\mathrm{O} 1 \mathrm{~s}$ spectra, which can be fitted with two peaks. The peak with a binding energy of $530.2 \mathrm{eV}$ is associated with the lattice oxygen (marked as $\mathrm{O}_{\mathrm{L}}$ ), whereas the other peak at $532.2 \mathrm{eV}$ can be attributed to the oxygen defects (marked as $\mathrm{O}_{\mathrm{V}}$ ) [40,41]. Obviously, more oxygen defects are found in $\mathrm{S} 1$ than in S4 probably because of the combined effects of the higher $\mathrm{Zn} / \mathrm{Fe}$ atomic ratio and smaller particle size.

Fig. 4a shows the magnetization versus magnetic field $(M-H)$ curves of the four zinc ferrite nanoparticles at room temperature. Table 1 presents the magnetic parameters. All the zinc ferrite nanoparticles have S-type shapes, which can be identified based on the paramagnetism of bulk $\mathrm{ZnFe}_{2} \mathrm{O}_{4}$. Saturation magnetization $\left(M_{\mathrm{s}}\right)$ increases from $\mathrm{S} 1$ to $\mathrm{S} 4$. S4 with a chemical composition of $\mathrm{Zn}_{0.438} \mathrm{Fe}_{2.562} \mathrm{O}_{4}$ exhibits the highest $M_{\mathrm{s}}$ of $81.30 \mathrm{emu} \mathrm{g}{ }^{-1}$. Magneton number $\left(\eta_{\mathrm{B}}\right)$, which is the saturation magnetization per formula unit in $\mu_{\mathrm{B}}$, can be calculated as follows [42]: 

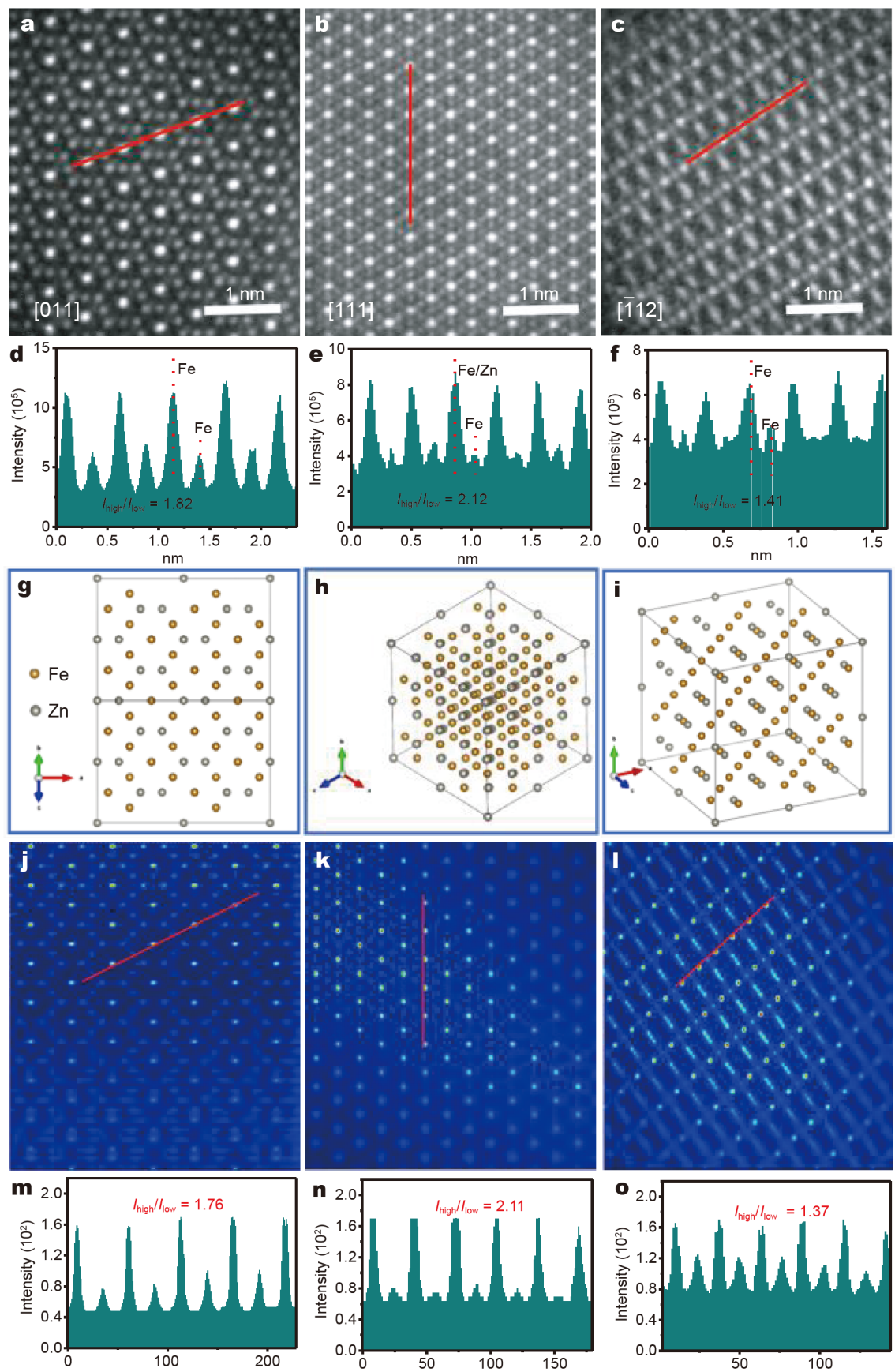

Figure 2 (a-c) Atomic HAADF-STEM images of $\mathrm{S} 1\left(\mathrm{Zn}_{1.186} \mathrm{Fe}_{1.814} \mathrm{O}_{4}\right)$ along the [011], [111], and [112] orientations, respectively. (d-f) The corresponding line intensity profiles for the atomic columns in $(\mathrm{a}-\mathrm{c})$. ( $\mathrm{g}-\mathrm{i}$ ) Perspective view of $\mathrm{Zn}_{38} \mathrm{Fe}_{58} \mathrm{O}_{128}$ supercell along the [011], [111], and [112] orientations. (j-l) Three theoretical STEM images simulated using QSTEM and projected along the [011], [111], and [112] zone axes. (m-o) The corresponding simulated line intensity profiles for the atomic columns in $(j-1)$.

$\eta_{\mathrm{B}}=\left(M \times M_{\mathrm{s}}\right) / 5585$,

where $M$ is the molecular weight. S1, S2, S3, and S4 have $\eta_{\mathrm{B}}$ values of $0.98,2.37,2.97$, and $3.43 \mu_{\mathrm{B}}$, respectively.
Fig. $4 \mathrm{~b}$ presents the magnified view of the corresponding magnetization curves when considering a low magnetic field. The residual magnetism $\left(M_{\mathrm{r}}\right)$ increases from 0.0035 to $6.49 \mathrm{emu} \mathrm{g}^{-1}$, whereas coercivity $\left(H_{\mathrm{c}}\right)$ varies from ap- 

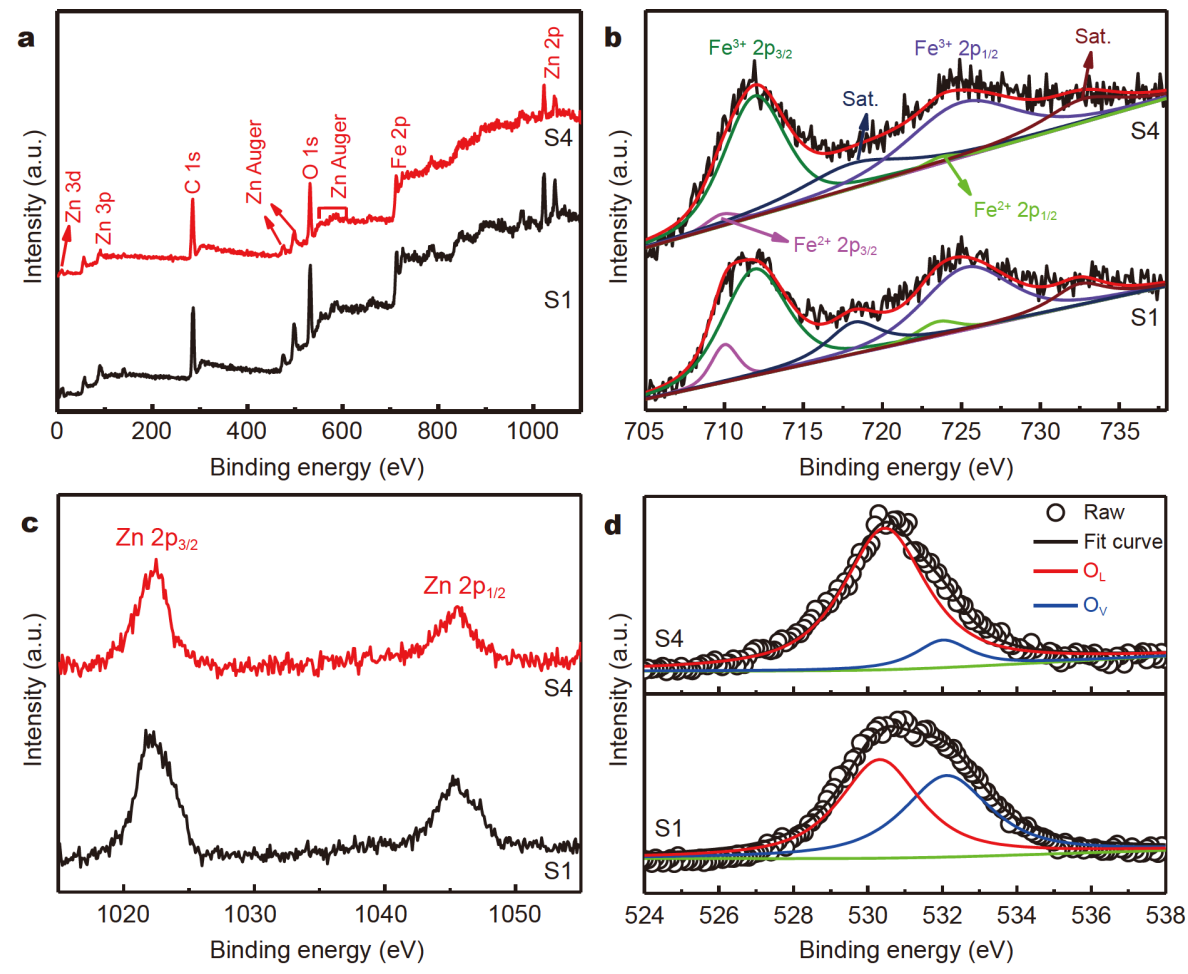

Figure 3 XPS spectra of S1 and S4: (a) survey scan, (b) Fe 2p, (c) Zn 2p, and (d) O 1 s.

proximately 1.44 to 45.60 Oe. The distinguishing magnetic properties associated with the nonstoichiometric zinc ferrite nanoparticles can be mainly attributed to the particle size, cation ratio, and cation redistribution at tetrahedral sites (A sublattices) and octahedral sites (B sublattices). According to the ferromagnetic theory of Nél's sublattice model [10], the magnetic moments of cations at the A or B sites are parallel within each sublattice, whereas the magnetic moments in the A sublattice are antiparallel to those in the B sublattice. The net magnetic moments of each formula unit cell can be attributed to the difference between the A (spin upward) and $\mathrm{B}$ (spin downward) sites; this phenomenon can be evaluated using Equation (2) $[13,43]$.

$M=\sum M_{\text {tet.(A) }}-\sum M_{\text {oct.(B) }}$,

where $\sum M_{\text {tet.(A) }}$ and $\sum M_{\text {oct.(B) }}$ are the sums of the magnetic moments with respect to the $\mathrm{A}$ and $\mathrm{B}$ sublattices, respectively. Stoichiometric $\mathrm{ZnFe}_{2} \mathrm{O}_{4}$ is a typical normal spinel ferrite, wherein $\mathrm{Zn}^{2+}$ primarily occupies the A sublattice and all the $\mathrm{Fe}^{3+}$ ions occupy the $\mathrm{B}$ sublattice. The spin associated with the $\mathrm{Fe}^{3+}$ ions in the B sublattice tends to be antiparallel because the spin magnetic moment of the $\mathrm{Zn}^{2+}$ ions in the A sublattice is zero. Based on the above results obtained using the HAADF-STEM images, the cation redistributions and chemical formulas of $\mathrm{S} 1$ $\left(\mathrm{Zn}_{1.186} \mathrm{Fe}_{1.814} \mathrm{O}_{4}\right), \mathrm{S} 2\left(\mathrm{Zn}_{0.633} \mathrm{Fe}_{2.367} \mathrm{O}_{4}\right), \mathrm{S} 3\left(\mathrm{Zn}_{0.481}-\mathrm{Fe}_{2.519} \mathrm{O}_{4}\right)$, and $\mathrm{S} 4\left(\mathrm{Zn}_{0.438} \mathrm{Fe}_{2.562} \mathrm{O}_{4}\right)$ can be expressed as $\left(\mathrm{Zn}_{1}\right)\left[\mathrm{Zn}_{0.186^{-}}\right.$ $\left.\mathrm{Fe}_{1.814}\right] \mathrm{O}_{4}, \quad\left(\mathrm{Zn}_{0.633} \mathrm{Fe}_{0.367}\right)\left[\mathrm{Fe}_{2}\right] \mathrm{O}_{4},\left(\mathrm{Zn}_{0.481} \mathrm{Fe}_{0.519}\right)-\left[\mathrm{Fe}_{2}\right] \mathrm{O}_{4}$, and $\left(\mathrm{Zn}_{0.438} \mathrm{Fe}_{0.562}\right)\left[\mathrm{Fe}_{2}\right] \mathrm{O}_{4}$, respectively. The round and square brackets represent the $\mathrm{A}$ and $\mathrm{B}$ sublattices, respectively, and the magnetic moments of $\mathrm{Fe}^{3+}$ and $\mathrm{Zn}^{2+}$ are 5.9 and $0 \mu_{\mathrm{B}}$, respectively $[44,45]$. Therefore, the net magnetic moments (NMMs) per formula unit of S1, S2, $\mathrm{S} 3$, and $\mathrm{S} 4$ can be obtained as $1.10,2.17,3.06$, and $3.32 \mu_{\mathrm{B}}$, respectively. These values are close to the $\eta_{\mathrm{B}}$ obtained based on the measured saturation magnetization (Table 1).

Fig. $4 \mathrm{c}-\mathrm{f}$ represent the temperature dependence of the zero-field-cooled (ZFC) and field-cooled (FC) magnetization curves of the zinc ferrite nanoparticles. The zinc ferrite nanoparticles were cooled from 300 to $5 \mathrm{~K}$ for measuring the ZFC magnetization. When the temperature reached $5 \mathrm{~K}$, the $\mathrm{FC}$ magnetization was recorded from 5 to $300 \mathrm{~K}$ in an external magnetic field of 100 Oe. For S1 and S2, the ZFC magnetization initially increases and subsequently decreases as the temperature increases from 5 to $300 \mathrm{~K}$. The ZFC magnetizations of S1 and S2 reach maximum magnetization values at 16.5 and $60.5 \mathrm{~K}$, respectively, corresponding to their blocking temperature $\left(T_{\mathrm{B}}\right)$. At temperatures lower than the blocking tempera- 

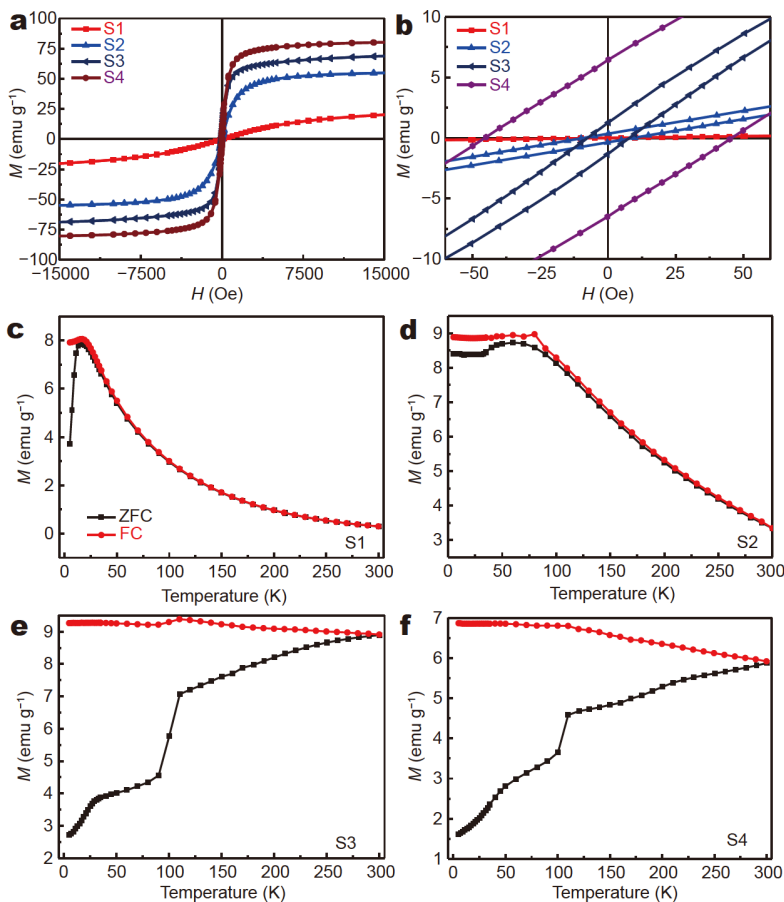

Figure 4 (a, b) $M-H$ loops of the four samples. ZFC/FC curves of (c) S1, (d) S2, (e) S3, and (f) S4.

ture $\left(T<T_{\mathrm{B}}\right)$, the magnetic moment of each nanoparticle of S1 and S2 is frozen under a local magnetic field and coherently oriented because of the magnetic anisotropy energy $[20,46]$. At temperatures higher than the blocking temperature $\left(T>T_{\mathrm{B}}\right)$, the orientation of the magnetic moment for each nanoparticle is unfrozen via thermal fluctuation. The magnetic moments are randomly oriented. Therefore, S1 and S2 show superparamagnetic features at temperatures higher than 16.5 and $60.5 \mathrm{~K}$, respectively. The FC magnetizations of S1 and S2 progressively increase below $T_{\mathrm{B}}$, suggesting the absence of dipolar interactions [47]. The superparamagnetic blocking diameter $\left(D_{\text {sp }}\right)$ can be estimated as follows [48]:

$D_{\mathrm{sp}}=\left[\frac{6 k_{\mathrm{B}} T}{\pi K} \ln \left(\frac{\tau}{\tau_{0}}\right)\right]^{1 / 3}$, where $k_{\mathrm{B}}$ is the Boltzmann constant, $K$ is the magnetocrystalline anisotropy constant, $T$ is the measured temperature, $\tau$ is approximately $100 \mathrm{~s}$ for SQUID measurement, and $\tau_{0}$ is approximately $10^{-9} \mathrm{~s}$. The effective anisotropy constants $\left(K_{\text {eff }}\right)$ of S1 and S2 calculated based on $T_{\mathrm{B}}$ and the particle sizes of S1 and S2 are 157.8 and $145.2 \mathrm{~kJ} \mathrm{~m}^{-3}$, respectively. The superparamagnetic blocking diameters of $\mathrm{S} 1$ and $\mathrm{S} 2$ at room temperature are 10.7 and $11.0 \mathrm{~nm}$, respectively. In S3 and S4, the ZFC curves monotonically increase as the temperature increases up to $300 \mathrm{~K}$; further, the FC curves do not tend to decline and overlap with the ZFC curves. These results indicate that the blocking temperatures of S3 and S4 are higher than $300 \mathrm{~K}$ and demonstrate that S3 and S4 show a ferromagnetic feature at room temperature. The FC curves of S3 and S4 are almost flat in the whole temperature range, implying the presence of a strong magnetic dipole-dipole interaction among the nanoparticles.

Fig. S7 shows the O K-edge X-ray magnetic circular dichroism (XMCD) spectra of zinc ferrite nanoparticles. $\mathrm{Zn}^{2+}$ can affect the $\mathrm{O} 2 \mathrm{p}-\mathrm{Fe} 3 \mathrm{~d}$ hybridizations. Fig. 5 depicts the Fe $L$-edge XMCD spectra of the four zinc ferrite nanoparticles recorded via circularly polarized Xrays with a magnetic field of $B= \pm 1 \mathrm{~T}$. Two XMCD peaks can be observed at the $L_{3}$ edge. The high- and low-energy peaks can be attributed to $\mathrm{Fe}^{3+}$ and $\mathrm{Fe}^{2+}$, respectively [4951]. The existence of $\mathrm{Fe}^{2+}$ can be attributed to the lattice distortion of oxygen defects and the changes in relative ratio. The same sign of the XMCD signals of $\mathrm{Fe}^{2+}$ and $\mathrm{Fe}^{3+}$ indicates their ferromagnetic coupling [49,52]. The orbital and spin moments of Fe were calculated based on the $\mathrm{XMCD}$ sum rules to analyze the structural and magnetic properties. Table 2 summarizes the spin magnetic moments (SMMs), orbital magnetic moments (OMMs), total magnetic moments (TMMs), and relative ratios of the spin magnetic moment (RSMM) of the zinc ferrite nanoparticles. Fig. S8 presents the relation of magnetization $\left(\eta_{\mathrm{B}}, \mathrm{NMM}, \mathrm{OMM}, \mathrm{SMM}\right.$, and TMM) with oxygen defect concentration and $\mathrm{Zn} / \mathrm{Fe}$ atom ratio. The SMM and OMM increase with the decreasing oxygen defect con-

Table 1 Comparison of the magnetic parameters of the zinc ferrite nanoparticles

\begin{tabular}{ccccccc}
\hline Samples & Chemical formula & $M_{\mathrm{r}}\left(\mathrm{emu} \mathrm{g}^{-1}\right)$ & $H_{\mathrm{c}}(\mathrm{Oe})$ & $M_{\mathrm{s}}\left(\mathrm{emu} \mathrm{g}^{-1}\right)$ & $\eta_{\mathrm{B}}{ }^{\mathrm{a}}\left(\mu_{\mathrm{B}}\right)$ & $\mathrm{NMM}^{\mathrm{b}}\left(\mu_{\mathrm{B}}\right)$ \\
\hline $\mathrm{S} 1$ & $\mathrm{Zn}_{1.186} \mathrm{Fe}_{1.814} \mathrm{O}_{4}$ & 0.0035 & 1.44 & 22.60 & 0.98 & 1.10 \\
$\mathrm{~S} 2$ & $\mathrm{Zn}_{0.633} \mathrm{Fe}_{2.367} \mathrm{O}_{4}$ & 0.35 & 9.16 & 55.76 & 2.37 & 2.17 \\
$\mathrm{~S} 3$ & $\mathrm{Zn}_{0.481} \mathrm{Fe}_{2.519} \mathrm{O}_{4}$ & 1.32 & 7.73 & 70.30 & 2.97 & 3.06 \\
$\mathrm{~S} 4$ & $\mathrm{Zn}_{0.438} \mathrm{Fe}_{2.562} \mathrm{O}_{4}$ & 6.49 & 45.60 & 81.30 & 3.43 & 3.32 \\
\hline
\end{tabular}

a) $\eta_{\mathrm{B}}$ was obtained from $M_{\mathrm{s}}$ per formula unit in $\mu_{\mathrm{B}}$. b) Net magnetic moment was calculated on the basis of the chemical formula unit cell. 

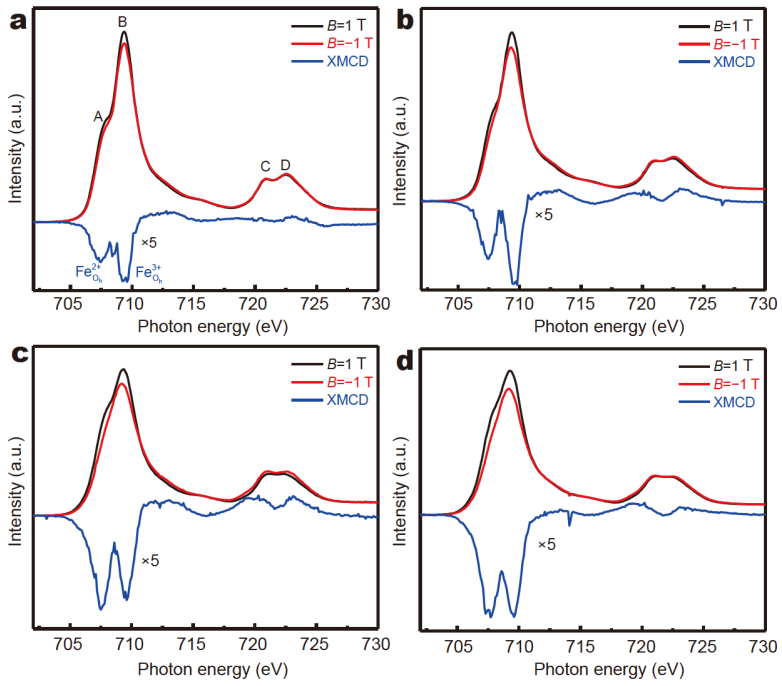

Figure 5 XMCD spectra of the Fe $L$-edge absorption of (a) S1, (b) S2, (c) S3, and (d) S4.

Table 2 SMM, OMM, TMM and RSMM of zinc ferrite nanoparticles

\begin{tabular}{ccccc}
\hline Samples & SMM & OMM & TMM & RSMM (\%) \\
\hline S1 & 0.1150 & 0.0652 & 0.1806 & 63.82 \\
S2 & 0.2755 & 0.0806 & 0.3561 & 77.37 \\
S3 & 0.4869 & 0.0914 & 0.5783 & 84.63 \\
S4 & 0.4922 & 0.2058 & 0.6980 & 70.52 \\
\hline
\end{tabular}

centration and $\mathrm{Zn} / \mathrm{Fe}$ atom ratio. Therefore, $\eta_{\mathrm{B}}$ and $M_{\mathrm{s}}$ improve. The OMM is frozen in small nanoparticles, which is accordant with the existence of the block temperatures in S1 and S2 (Fig. 4d).

Based on the XRD and XPS results, the nonstoichiometric zinc ferrite nanoparticles have numerous oxygen defects, and S1 and S2 contain some $\mathrm{ZnO}$ impurities. Makovec et al. [38] reported the presence of oxygen vacancies in nonstoichiometric zinc ferrite nanoparticles when $\mathrm{Zn} / \mathrm{Fe}$ is greater than 0.5 . They suggested that oxygen vacancies can destroy super-exchange interactions and decrease magnetization. The four zinc ferrite nanoparticles were annealed at $473 \mathrm{~K}$ in air for $1 \mathrm{~h}$ to investigate the effect of oxygen vacancies on the magnetic properties. The samples annealed in air are marked as S1A. Fig. 6a shows the XRD patterns of $S 1$ before and after annealing in air. The diffraction peaks of the $\mathrm{ZnO}$ impurities in S1, which are marked with red shuriken, completely disappear after the air annealing treatment. However, the morphological characteristics and distribution of S1 are slightly influenced by the air annealing treatment (TEM images in Fig. 6b). Fig. S9 presents the magnified part of the predominant (311) diffraction peaks of S1 and S1-A. The diffraction peaks shift to a lower degree after the air annealing treatment. Therefore, the lattice parameters are enhanced probably because of the
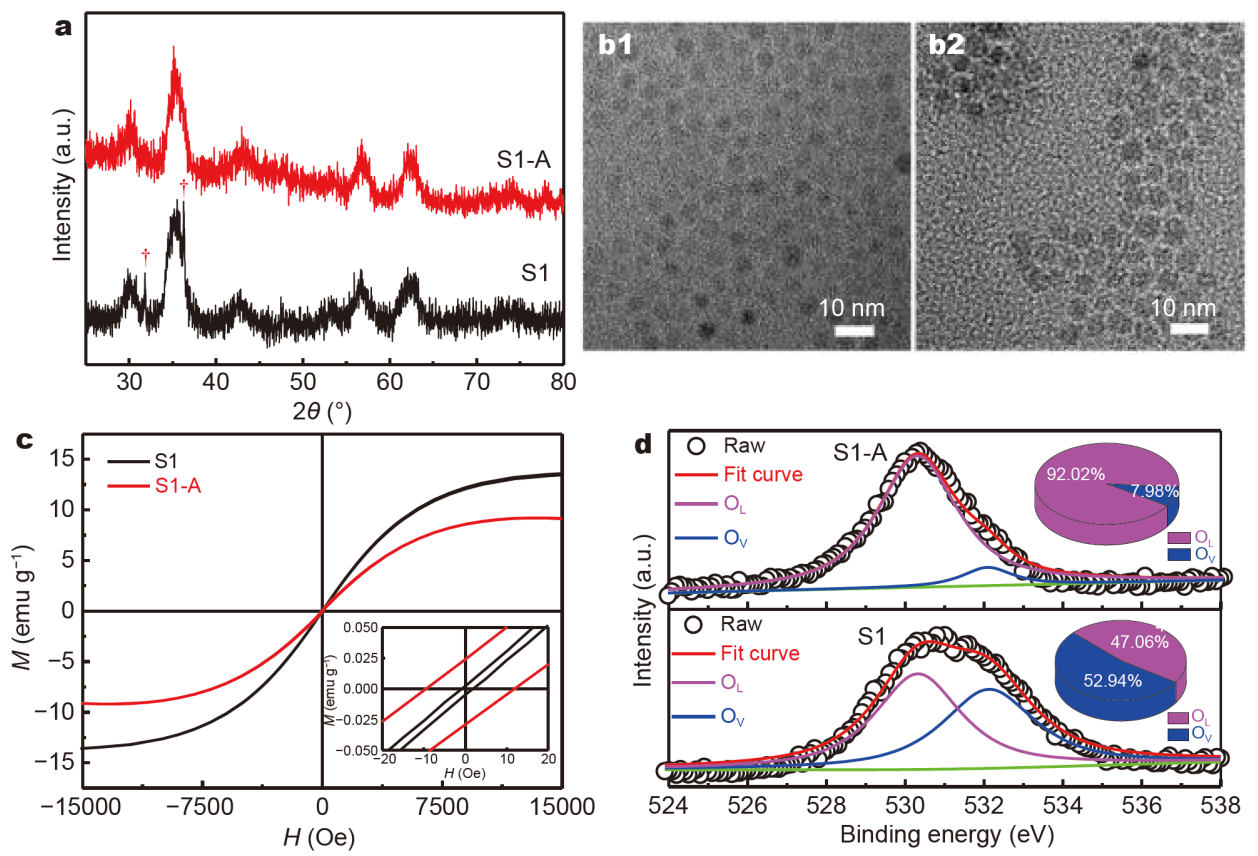

Figure 6 (a) XRD patterns, (b) TEM images, (c) $M-H$ curves, and (d) O 1s XPS spectra of S1 before and after annealing at $473 \mathrm{~K}$ in air for $1 \mathrm{~h}$. S1 annealed in air at $473 \mathrm{~K}$ is marked as $\mathrm{S} 1-\mathrm{A}$. 
entry of oxygen into the lattice and the repair of oxygen defects. Thus, $\mathrm{Fe}^{3+}-\mathrm{O}^{2-}-\mathrm{Fe}^{3+}$ antiferromagnetic couplings are formed. In addition, the Fe $2 p$ XPS spectra (Fig. S5) and the corresponding fitting results (Table S2) indicate that the amount of $\mathrm{Fe}^{2+}$ considerably decreases after the air annealing treatment. These results suggest a change in the chemical environment of $\mathrm{Fe}^{3+}$. Furthermore, the extrinsic impurity phase of the $\mathrm{ZnO}$ impurities in $\mathrm{S} 1$ can be attributed to the high $\mathrm{Zn} / \mathrm{Fe}$ atom ratio and abundant oxygen defects. Fig. $6 \mathrm{c}$ presents the $M-H$ curves of $S 1$ and $\mathrm{S} 1-\mathrm{A}$ measured at room temperature. The paramagnetic contribution of samples in $M-H$ curves is subtracted. The $M_{\mathrm{s}}$ of S1 decreases after the air annealing treatment. This result is considerably interesting because the nonmagnetic phase of $\mathrm{ZnO}$ impurities disappears and crystallinity improves after the air annealing treatment. Further, the magnetic properties are enhanced. This abnormal phenomenon was investigated based on the highresolution O 1s XPS spectra of S1 and S1-A (Fig. 6d). The oxygen defect concentration decreases from $52.94 \%$ to $7.98 \%$. The $M-H$ curves and high-resolution O 1s XPS spectra of the other three samples before and after air annealing were also characterized (Fig. S10). The $M_{\mathrm{s}}$ values and oxygen defect concentrations of all the samples decrease after the air annealing treatment. This result suggests that oxygen defects considerably affect the magnetic properties of zinc ferrite nanoparticles. The air annealing treatment can reduce oxygen defects, causing some of the $\mathrm{Fe}^{3+}-\mathrm{O}_{\mathrm{V}}-\mathrm{Fe}^{3+}$ ferrimagnetic couplings to transform into the $\mathrm{Fe}^{3+}-\mathrm{O}^{2-}-\mathrm{Fe}^{3+}$ antiferromagnetic coupling in the spinel structure.

Further, a $2 \times 2 \times 2$ stoichiometric zinc ferrite supercell with or without oxygen defects was constructed (Fig. S11) to investigate the effect of oxygen defect on the magnetization of zinc ferrite. The related magnetic properties were estimated by applying the GGA + U method. Fig. $7 \mathrm{a}$ shows the spin-charge density image of the $2 \times 2 \times 2$ $\mathrm{ZnFe}_{2} \mathrm{O}_{4}$ supercell without oxygen defects but with a rigorous $\mathrm{Fe}^{3+}-\mathrm{O}^{2-}-\mathrm{Fe}^{3+}$ antiferromagnetic coupling. The related total density of state (DOS) spectrum (Fig. $7 \mathrm{~b}$ ) denotes that the spin-up and spin-down states are symmetric, indicating antiferromagnetic properties. However, when an oxygen atom is removed from the $2 \times 2 \times 2$ $\mathrm{ZnFe}_{2} \mathrm{O}_{4}$ supercell, the spin-charge density spectra (Fig. 7c) indicate that the rigorous $\mathrm{Fe}^{3+}-\mathrm{O}^{2-}-\mathrm{Fe}^{3+}$ antiferromagnetic coupling is transformed into $\mathrm{Fe}^{3+}-\mathrm{O}_{\mathrm{V}}-\mathrm{Fe}^{3+}$ ferrimagnetic couplings. Further, the spin-up and spindown states in the total DOS spectrum (Fig. 7d) become asymmetric. Table $\mathrm{S} 3$ reveals the magnetization of specific $\mathrm{Zn}, \mathrm{Fe}$, and $\mathrm{O}$ in the $2 \times 2 \times 2 \mathrm{ZnFe}_{2} \mathrm{O}_{4}$ supercell without
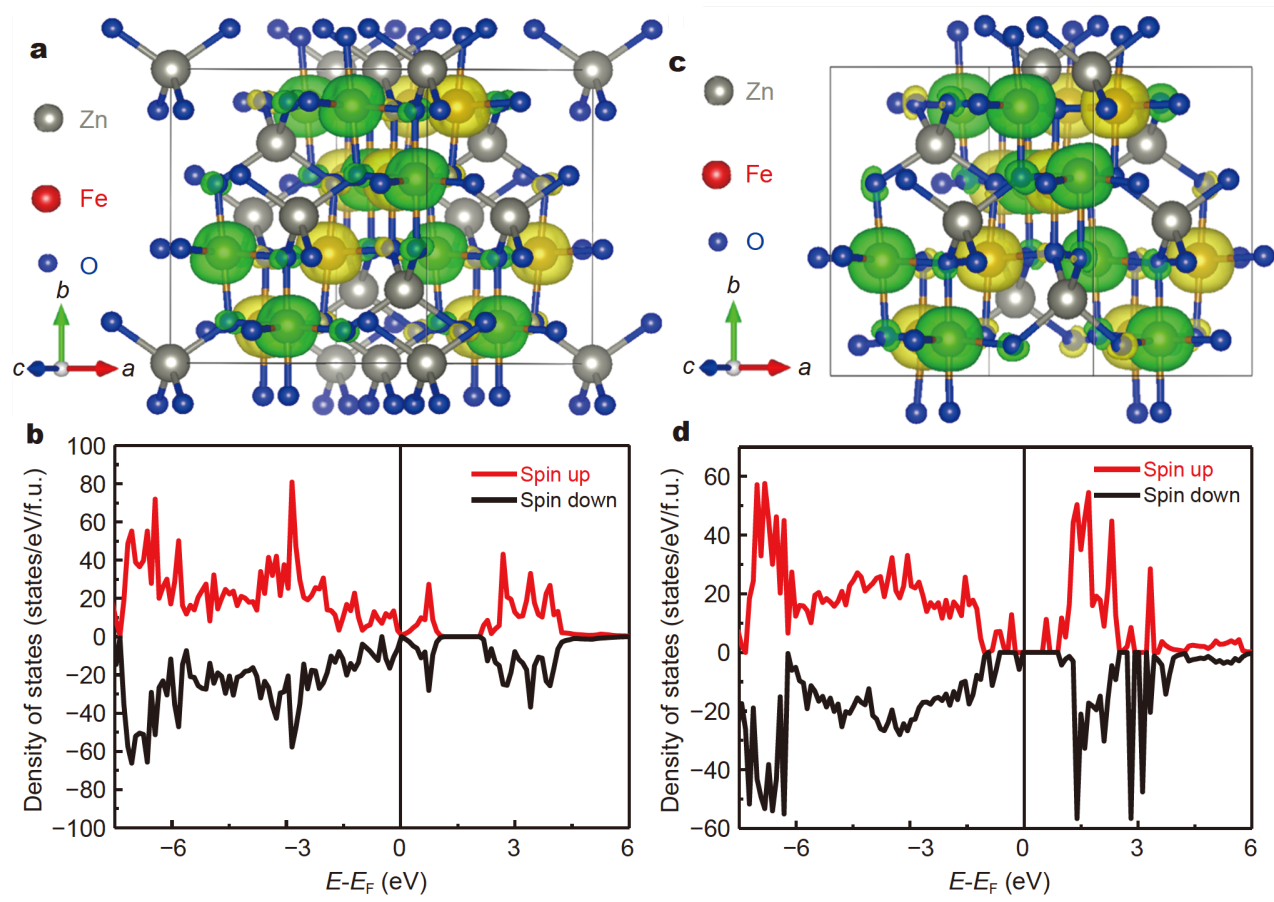

Figure 7 (a) Spin-charge density image and (b) total DOS spectrum of a $2 \times 2 \times 2 \mathrm{ZnFe}_{2} \mathrm{O}_{4}$ supercell without oxygen defects. (c) Spin-charge density image and (d) total DOS spectrum of a $2 \times 2 \times 2 \mathrm{ZnFe}_{2} \mathrm{O}_{4}$ supercell with one oxygen defect. 
and with one oxygen defect. The polarization state and magnetization of $\mathrm{Zn}, \mathrm{Fe}$, and $\mathrm{O}$ remarkably improve when one oxygen defect forms. The total magnetization changes from a negligible value of 0.002 to $-1.902 \mu_{B}$ when considering the construction of one oxygen defect. Therefore, oxygen defects can induce ferrimagnetic properties in zinc ferrites.

\section{CONCLUSION}

In summary, monodisperse nonstoichiometric zinc ferrite nanoparticles are fabricated through thermal decomposition in this study. The $\mathrm{Zn} / \mathrm{Fe}$ atom ratio can be controlled from approximately 0.65 to 0.17 by tuning the surfactant ratios; further, the particle size can be changed from approximately 4.1 to $32.2 \mathrm{~nm}$. Zinc ferrite nanoparticles with a particle size of $<10 \mathrm{~nm}$ contain some extrinsic $\mathrm{ZnO}$ impurities that can be probably attributed to the excess $\mathrm{Zn}$ concentration and oxygen defects. Magnetic transition from superparamagnetism to ferromagnetism can be observed with the decreasing $\mathrm{Zn} / \mathrm{Fe}$ atom ratios and increasing particle size. Further, saturation magnetization is observed to improve because of the increasing spin magnetic moments of $\mathrm{Fe}^{3+}$ and the unfrozen orbital magnetic moments. After the air annealing treatment was conducted, the zinc ferrite nanoparticles show reduced saturation magnetization with decreased oxygen defects, which can induce the transformation of $\mathrm{Fe}^{3+}-\mathrm{O}_{\mathrm{V}}-\mathrm{Fe}^{3+}$ ferrimagnetic coupling into $\mathrm{Fe}^{3+}-\mathrm{O}^{2-}-\mathrm{Fe}^{3+}$ antiferromagnetic coupling in the spinel structure. These results indicate that the $\mathrm{Zn} / \mathrm{Fe}$ atom ratios and oxygen defects can cause ferromagnetic ordering in nonstoichiometric zinc ferrite nanoparticles, which are quite different from bulk $\mathrm{ZnFe}_{2} \mathrm{O}_{4}$. This work provides new insights regarding the origin and regulation of the magnetic properties of ferrites.

Received 19 September 2020; accepted 15 December 2020; published online 23 February 2021

1 Xiong QQ, Tu JP, Shi SJ, et al. Ascorbic acid-assisted synthesis of cobalt ferrite $\left(\mathrm{CoFe}_{2} \mathrm{O}_{4}\right)$ hierarchical flower-like microspheres with enhanced lithium storage properties. J Power Sources, 2014, 256: 153-159

2 Bigham A, Foroughi F, Motamedi $\mathrm{M}$, et al. Multifunctional nanoporous magnetic zinc silicate- $\mathrm{ZnFe}_{2} \mathrm{O}_{4}$ core-shell composite for bone tissue engineering applications. Ceramics Int, 2018, 44: 11798-11806

3 Liao W, Zhou G. Conditions for magnetic and electronic properties of ultrathin Ni-Fe hydroxide nanosheets as catalysts: a DFT+U study. Sci China Mater, 2017, 60: 664-673

4 Daffé N, Gavrilov V, Neveu S, et al. Small $\mathrm{CoFe}_{2} \mathrm{O}_{4}$ magnetic nanoparticles in ferrofluids, influence of the synthesis on the magnetic anisotropies. J Magn Magn Mater, 2019, 477: 226-231
5 Zheng X, Feng J, Zong $\mathrm{Y}$, et al. Hydrophobic graphene nanosheets decorated by monodispersed superparamagnetic $\mathrm{Fe}_{3} \mathrm{O}_{4}$ nanocrystals as synergistic electromagnetic wave absorbers. J Mater Chem C, 2015, 3: 4452-4463

6 He DX, Qiu Y, Li LL, et al. Large-scale solvent-thermal synthesis of graphene/magnetite/conductive oligomer ternary composites for microwave absorption. Sci China Mater, 2015, 58: 566-573

7 Maiti D, Saha A, Devi PS. Surface modified multifunctional $\mathrm{ZnFe}_{2} \mathrm{O}_{4}$ nanoparticles for hydrophobic and hydrophilic anticancer drug molecule loading. Phys Chem Chem Phys, 2016, 18: 1439-1450

8 Wang S, Sun Z, Hou Y. Engineering nanoparticles toward the modulation of emerging cancer immunotherapy. Adv Healthcare Mater, 2020, 9: 2000845

9 Zhu K, Ju Y, Xu J, et al. Magnetic nanomaterials: chemical design, synthesis, and potential applications. Acc Chem Res, 2018, 51: 404-413

10 Morrish AH. The Physical Principle of Magnetism. New York: IEEE Press, 2001

11 Dionne GF. Magnetic Oxides. New York: Spinger-Verlag, LLC, 2009

12 Kodama RH, Berkowitz AE, McNiff Jr. EJ, et al. Surface spin disorder in ferrite nanoparticles. Mater Sci Forum, 1996, 235-238: 643-650

13 Yadav RS, Havlica J, Masilko J, et al. Structural, cation distribution, and magnetic properties of $\mathrm{CoFe}_{2} \mathrm{O}_{4}$ spinel ferrite nanoparticles synthesized using a starch-assisted sol-gel auto-combustion method. J Supercond Nov Magn, 2015, 28: 1851-1861

14 Yang Y, Liu X, Yang Y, et al. Synthesis of nonstoichiometric zinc ferrite nanoparticles with extraordinary room temperature magnetism and their diverse applications. J Mater Chem C, 2013, 1: 2875

15 Nath BK, Chakrabarti PK, Das S, et al. Mössbauer, X-ray diffraction and AC susceptibility studies on nanoparticles of zinc substituted magnesium ferrite. Eur Phys J B, 2004, 39: 417-425

16 Smit J, Wijn HPJ. Ferrites. Philips Technical Library, Eindhoven, Netherland, 1959

17 Schiessl W, Potzel W, Karzel H, et al. Magnetic properties of the $\mathrm{ZnFe}_{2} \mathrm{O}_{4}$ spinel. Phys Rev B, 1996, 53: 9143-9152

18 Yao C, Zeng Q, Goya GF, et al. $\mathrm{ZnFe}_{2} \mathrm{O}_{4}$ nanocrystals: Synthesis and magnetic properties. J Phys Chem C, 2007, 111: 12274-12278

19 Néel L. Superparamagnétisme des grains très fins antiferromagnétiques. Compt Rend, 1961, 252: 4075

20 Yelenich OV, Solopan SO, Kolodiazhnyi TV, et al. Magnetic properties and high heating efficiency of $\mathrm{ZnFe}_{2} \mathrm{O}_{4}$ nanoparticles. Mater Chem Phys, 2014, 146: 129-135

21 Fang Z, Zhang L, Qi $\mathrm{H}$, et al. Nanosheet assembled hollow $\mathrm{ZnFe}_{2} \mathrm{O}_{4}$ microsphere as anode for lithium-ion batteries. J Alloys Compd, 2018, 762: 480-487

22 Zhang Y, Wu Y, Qin Q, et al. A study of the mechanism of microwave-assisted ball milling preparing $\mathrm{ZnFe}_{2} \mathrm{O}_{4}$. J Magn Magn Mater, 2016, 409: 6-9

23 Ismail $\mathrm{M}$, Hao $\mathrm{A}$, Huang $\mathrm{W}$, et al. Coexistence of unipolar and bipolar switching in nanocrystalline spinel ferrite $\mathrm{ZnFe}_{2} \mathrm{O}_{4}$ thin films synthesized by sol-gel method. Appl Phys Lett, 2018, 113: 152103

24 Park J, Porter MD, Granger MC. Silica encapsulation of ferrimagnetic zinc ferrite nanocubes enabled by layer-by-layer polyelectrolyte deposition. Langmuir, 2015, 31: 3537-3545

25 Rozman M, Drofenik M. Hydrothermal synthesis of manganese 
zinc ferrites. J Am Ceramic Soc, 1995, 78: 2449-2455

26 Blanco-Gutierrez V, Saez-Puche R, Torralvo-Fernandez MJ. Superparamagnetism and interparticle interactions in $\mathrm{ZnFe}_{2} \mathrm{O}_{4}$ nanocrystals. J Mater Chem, 2012, 22: 2992

27 Singh JP, Kaur B, Sharma A, et al. Mechanistic insights into the interaction between energetic oxygen ions and nanosized $\mathrm{ZnFe}_{2} \mathrm{O}_{4}$ : XAS-XMCD investigations. Phys Chem Chem Phys, 2018, 20: 12084-12096

28 Rodríguez Torres CE, Golmar F, Ziese M, et al. Evidence of defectinduced ferromagnetism in $\mathrm{ZnFe}_{2} \mathrm{O}_{4}$ thin films. Phys Rev B, 2011, 84: 064404

29 Salcedo Rodríguez KL, Stewart SJ, Mendoza Zélis PM, et al. Role of defects on the magnetic behaviour of the geometrically frustrated spinel $\mathrm{ZnFe}_{2} \mathrm{O}_{4}$. J Alloys Compd, 2018, 752: 289-295

30 Zviagin V, Kumar Y, Lorite I, et al. Ellipsometric investigation of $\mathrm{ZnFe}_{2} \mathrm{O}_{4}$ thin films in relation to magnetic properties. Appl Phys Lett, 2016, 108: 131901

31 Sahu BN, Suresh KG, Venkataramani N, et al. Temperature and field dependent magnetization studies on nano-crystalline $\mathrm{ZnFe}_{2} \mathrm{O}_{4}$ thin films. AIP Adv, 2018, 8: 056118

32 Sapna, Budhiraja N, Kumar V, et al. Shape-controlled synthesis of superparamagnetic $\mathrm{ZnFe}_{2} \mathrm{O}_{4}$ hierarchical structures and their comparative structural, optical and magnetic properties. Ceramics Int, 2019, 45: 1067-1076

33 Zhao H, Liu R, Zhang Q, et al. Effect of surfactant amount on the morphology and magnetic properties of monodisperse $\mathrm{ZnFe}_{2} \mathrm{O}_{4}$ nanoparticles. Mater Res Bull, 2016, 75: 172-177

34 Xue H, Li Z, Wang X, et al. Facile synthesis of nanocrystalline zinc ferrite via a self-propagating combustion method. Mater Lett, 2007, 61: 347-350

35 Han JK, Choi HJ. Non-stoichiometric zinc-doped spinel ferrite nanoparticles with enhanced magnetic property and their magnetorheology. Colloid Polym Sci, 2018, 296: 405-409

36 Seetha Rama Raju V. Synthesis of non-stoichiometric zinc ferrite for electromagnetic wave absorber applications. Mater Sci Eng-B, 2017, 224: 88-92

37 Venkateshvaran D, Althammer M, Nielsen A, et al. Epitaxial $\mathrm{Zn}_{x} \mathrm{Fe}_{3 x} \mathrm{O}_{4}$ thin films: A spintronic material with tunable electrical and magnetic properties. Phys Rev B, 2009, 79: 134405

38 Makovec D, Drofenik M. Non-stoichiometric zinc-ferrite spinel nanoparticles. J Nanopart Res, 2008, 10: 131-141

39 Gao XC, Ma XX, Kang X, et al. Oxidative absorption of NO by sodium persulfate coupled with $\mathrm{Fe}^{2+}, \mathrm{Fe}_{3} \mathrm{O}_{4}$, and $\mathrm{H}_{2} \mathrm{O}_{2}$. Environ Prog Sustain Energy, 2015, 34: 117-124

40 Motaung DE, Mhlongo GH, Nkosi SS, et al. Shape-selective dependence of room temperature ferromagnetism induced by hierarchical ZnO nanostructures. ACS Appl Mater Interfaces, 2014, 6: 8981-8995

41 Sun Y, Zong Y, Feng J, et al. Oxygen vacancies driven size-dependent $\mathrm{d}^{0}$ room temperature ferromagnetism in well-dispersed dopant-free $\mathrm{ZnO}$ nanoparticles and density functional theory calculation. J Alloys Compd, 2018, 739: 1080-1088

42 Topkaya R, Baykal A, Demir A. Yafet-Kittel-type magnetic order in $\mathrm{Zn}$-substituted cobalt ferrite nanoparticles with uniaxial aniso- tropy. J Nanopart Res, 2013, 15: 1359

43 Zeng X, Zhang J, Zhu S, et al. Direct observation of cation distributions of ideal inverse spinel $\mathrm{CoFe}_{2} \mathrm{O}_{4}$ nanofibres and correlated magnetic properties. Nanoscale, 2017, 9: 7493-7500

44 Lacorre P, Pannetier J, Pebler J, et al. Ordered magnetic frustration: XVII. is $\mathrm{BaMnFeF}_{7}$ frustrated? Mössbauer spectroscopy, magnetic susceptibility, and magnetic structure at $2 \mathrm{~K}$. J Solid State Chem, 1992, 101: 296-308

45 Felner I, Yaron U, Nowik I, et al. New magnetic phases in the LaSr-Cu-O system. Physica C-Supercond, 1992, 198: 14-18

46 Bedanta S, Kleemann W. Supermagnetism. J Phys D-Appl Phys, 2009, 42: 013001

47 Pérez N, Bartolomé F, García LM, et al. Nanostructural origin of the spin and orbital contribution to the magnetic moment in $\mathrm{Fe}_{3-x} \mathrm{O}_{4}$ magnetite nanoparticles. Appl Phys Lett, 2009, 94: 093108

48 Krishnan KM. Fundamentals and Applications of Magnetic Materials. Seattle: Oxford University Press, 2016

49 Zhang W, Wong PKJ, Zhang D, et al. XMCD and XMCD-PEEM studies on magnetic-field-assisted self-assembled 1D nanochains of spherical ferrite particles. Adv Funct Mater, 2017, 27: 1701265

50 Antonov VN, Harmon BN, Yaresko AN. Electronic structure and $\mathrm{X}$-ray magnetic circular dichroism in $\mathrm{Fe}_{3} \mathrm{O}_{4}$ and $\mathrm{Mn}$-, $\mathrm{Co}$-, or $\mathrm{Ni}$ substituted $\mathrm{Fe}_{3} \mathrm{O}_{4}$. Phys Rev B, 2003, 67: 024417

51 Genuzio F, Menteş TO, Freindl K, et al. Chemistry-dependent magnetic properties at the FeNi oxide-metal interface. J Mater Chem C, 2020, 8: 5777-5785

52 Zhu Y, Zhan Q, Yang JC, et al. Enhanced structural and magnetic coupling in a mesocrystal-assisted nanocomposite. ACS Appl Mater Interfaces, 2016, 8: 1104-1111

Acknowledgements This work was financially supported by the National Natural Science Foundation of China (51572218, 11504293 and 11904275), the Natural Science Foundation of Shaanxi Province (2019JM-138), the Scientific Research Program Funded by Shaanxi Provincial Education Department (18JK0786, 19JK0413 and 20JK0946), and the Key Project of Research and Development of Shaanxi Province (2018ZDCXL-GY-08-05). The staff of Singapore Synchrotron Light Source and beam time from SINS beamline were acknowledged for their assistance.

Author contributions Sun Y performed the experiments and theoretical calculation; Deng $X$ conducted the STEM characterization and QSTEM analysis; Li X, Peng Y, and Zheng X designed the project; Chi X carried out the XMCD characterization and analysis; Zong Y completed the XPS characterization; Deng $X$ and Zhang J performed the EELS analysis; Feng J performed the TEM characterization; Shi $Z$ performed the magnetic analysis; Sun Y, Li X, and Zheng X wrote the draft of manuscript; Li $\mathrm{X}$ and Zheng $\mathrm{X}$ revised the manuscript. All authors contributed to the general discussion and checked the manuscript.

Conflict of interest The authors declare no conflict of interest.

Supplementary information Experimental details and supporting data are available in the online version of the paper. 


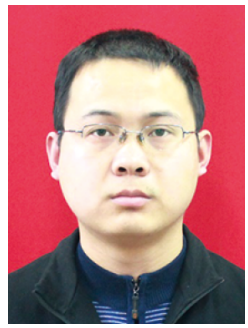

Yong Sun received his BSc degree from Northwest University in 2011 . He is currently a PhD candidate at the School of Physics, Northwest University. He was an exchange student of $\mathrm{Na}$ nyang Technological University (NTU) in Singapore (November 2019-April 2020). His research focuses on magnetic materials and microwave absorption materials.

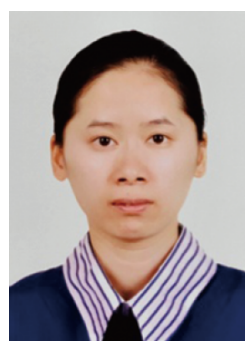

Xia Deng received her $\mathrm{BSc}$ and $\mathrm{PhD}$ degrees from Lanzhou University in 2011 and 2016, respectively. Then, she joined Lanzhou University as a lecturer. She is interested in electron microscopy and low-dimensional magnetic nanostructures for energy storage and drug delivery applications.

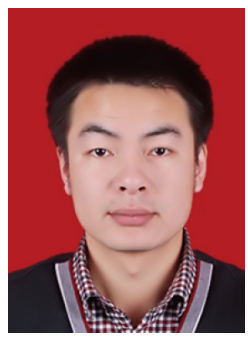

Xinghua $\mathrm{Li}$ received his $\mathrm{BSc}$ and $\mathrm{PhD}$ degrees from Lanzhou University in 2008 and 2013, respectively. Then, he joined Northwest University as a lecturer. He worked as a Postdoctoral Fellow at King Abdullah University of Science and Technology, Kingdom of Saudi Arabia (December 2017-June 2019). Currently, he is a professor at Northwest University. His current research interests are magnetic nanostructures and functional nanomaterials for microwave absorption and energy storage applications.

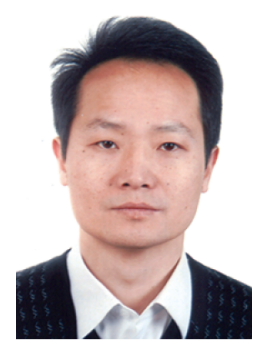

Yong Peng received his $\mathrm{PhD}$ degree from the University of Salford in 2004. Then, he worked as a research associate at the University of Sheffield. In 2010, he joined Lanzhou University as a Cuiying distinguished professor. He is interested in developing magneto-related instruments and in situ electron microscopes and characterizing the microstructures and dynamical behaviors of low-dimensional magnetic materials and devices.

\section{非化学计量比锌铁氧体中阳离子比与氧缺陷对其 磁性转变的调控研究}

孙勇 $^{1 \dagger}$, 邓霞 ${ }^{\dagger \dagger}$, 宗妍 ${ }^{1,2}$, 李兴华 ${ }^{1,2^{*}}$, 张军伟 ${ }^{4}$, 冯娟 ${ }^{1,2}$, 池啸 ${ }^{*^{*}}$, 史振华 ${ }^{6}$, 郑新亮 ${ }^{1,2}$, 彭勇 ${ }^{*}$

摘要 本文采用热解法制备了粒径在4.1-32.2 nm范围内可调的单 分散非化学计量比锌铁氧体纳米颗粒. 当颗粒尺寸小于 $10 \mathrm{~nm}$ 时, 样品中含有少量的非本征 $\mathrm{ZnO}$ 杂质相, 且空气退火后该杂质相消 失. 锌铁氧体中锌/铁原子比与氧缺陷浓度均随着颗粒尺寸的增大 而降低, 导致其从超顺磁性转变为铁磁性. 磁性圆二色谱表明, 随 着 $\mathrm{Zn} / \mathrm{Fe}$ 比的增加, $\mathrm{Fe}^{3+}$ 的自旋磁矩减小, 轨道磁矩冻结, 饱和磁化 强度降低. 经过空气退火, 所有样品的饱和磁化强度降低, 表明氧缺 陷 $\left(\mathrm{O}_{\mathrm{V}}\right)$ 对其磁性有很大影响. 空气退火会降低氧缺陷含量, 部分 $\mathrm{Fe}^{3+}-\mathrm{O}_{\mathrm{V}}-\mathrm{Fe}^{3+}$ 铁磁耦合转变为 $\mathrm{Fe}^{3+}-\mathrm{O}^{2-}-\mathrm{Fe}^{3+}$ 反铁磁耦合. 该工作通 过调控化学计量比和氧缺陷实现了对锌铁氧体磁性的调节, 为理 解和调控铁氧体的磁学性质提供了新的思路. 